\title{
Retraction Note: Meta-analysis of the effect of percutaneous coronary intervention on chronic total coronary occlusions
}

\author{
Ruogu Li ${ }^{1 \dagger}$, Shuansuo Yang ${ }^{2 *}$, Lei Tang ${ }^{3}$, Yiqing Yang ${ }^{4}$, Hui Chen ${ }^{1}$, Shaofeng Guan ${ }^{1}$, Wenzheng Han ${ }^{1}$, Hua Liu', \\ Jinjie Dai ${ }^{1}$, Qian Gan', Weiyi Fang ${ }^{1}$ and Xinkai Qu ${ }^{1 *}$
}

\section{Retraction}

The Publisher and Editor regretfully retract this article [1] because the peer-review process was inappropriately influenced and compromised. As a result, the scientific integrity of the article cannot be guaranteed. A systematic and detailed investigation suggests that a third party was involved in supplying fabricated details of potential peer reviewers for a large number of manuscripts submitted to different journals. In accordance with recommendations from COPE we have retracted all affected published articles, including this one. It was not possible to determine beyond doubt that the authors of this particular article were aware of any third party attempts to manipulate peer review of their manuscript.

\begin{abstract}
Author details
'Department of Cardiology, Shanghai Chest Hospital, Shanghai Jiaotong University, NO.241, Huaihai Xi Road, Xuhui District, Shanghai 200030, China. ${ }^{2}$ Department of Cardiology, Central Hospital, Fengxian District, Shanghai 201400, China. ${ }^{3}$ School of Medical Graduate, Shanghai Jiaotong University, Shanghai 200025, China. ${ }^{4}$ Department of Cardiovascular Research, Shanghai Chest Hospital, Shanghai Jiaotong University, Shanghai 200030, China.
\end{abstract}

Received: 15 February 2015 Accepted: 16 February 2015

Published online: 27 March 2015

\section{Reference}

1. Li R, Yang S, Tang L, Yang Y, Chen H, Guan S, et al. Meta-analysis of the effect of percutaneous coronary intervention on chronic total coronary occlusions. J Cardiothoracic Surgery. 2014;9:41.

\footnotetext{
*Correspondence: shuansuoyang11@163.com; yangshuansuo@hotmail.com ${ }^{\dagger}$ Equal contributors

${ }^{2}$ Department of Cardiology, Central Hospital, Fengxian District, Shanghai 201400, China

'Department of Cardiology, Shanghai Chest Hospital, Shanghai Jiaotong University, NO.241, Huaihai Xi Road, Xuhui District, Shanghai 200030, China
}

\section{Submit your next manuscript to BioMed Central and take full advantage of:}

- Convenient online submission

- Thorough peer review

- No space constraints or color figure charges

- Immediate publication on acceptance

- Inclusion in PubMed, CAS, Scopus and Google Scholar

- Research which is freely available for redistribution

\section{Biomed Central}

